\title{
Intravitreal moxifloxacin in the management of Ochrobactrum intermedium endophthalmitis due to metallic intraocular foreign body
}

This article was published in the following Dove Press journal:

Clinical Ophthalmology

26 August 2013

Number of times this article has been viewed

\section{David J Jacobs ${ }^{1,2}$ \\ Thomas J Grube 3 \\ Harry W Flynn Jr ${ }^{4}$ \\ Craig M Greven ${ }^{5}$ \\ Avinash Pathengay ${ }^{6}$ \\ Darlene Miller ${ }^{4}$ \\ Robert F Sanke ${ }^{1,2}$ \\ Joseph Thorman ${ }^{7}$}

'Trinity Regional Eyecare, Minot, ND, USA; ${ }^{2}$ School of Medicine and Health Sciences, University of North Dakota, Grand Forks, ND, USA; ${ }^{3}$ Grube Retina Clinic, Mandan, ND, USA; ${ }^{4}$ Bascom Palmer Eye Institute, University of Miami, Miami, FL, USA; ${ }^{5}$ Department of Ophthalmology, Wake Forest University Eye Center, Winston-Salem, NC, USA; 'LV Prasad Eye Institute, Hyderabad, India; ${ }^{7}$ Rolla Eye Clinic, ND, USA
Correspondence: David J Jacobs

Trinity Regional Eyecare, 28I5 16th

Street Southwest, Minot, ND 5870I, USA

Email jacobs.retina@gmail.com

\begin{abstract}
A healthy 34-year-old man presented with Ochrobactrum intermedium endophthalmitis due to a metallic intraocular foreign body. After vitrectomy, lensectomy, removal of the metallic intraocular foreign body, intravitreal vancomycin and ceftazidime, and systemic ciprofloxacin, intraocular inflammation worsened. Repeat vitreous culture confirmed persistent endophthalmitis due to multidrug-resistant $O$. intermedium. The endophthalmitis successfully resolved after the administration of intravitreal moxifloxacin.
\end{abstract}

Keywords: moxifloxacin, Ochrobactrum intermedium, endophthalmitis, intraocular foreign body

\section{Introduction}

Endophthalmitis can cause severe visual loss following open-globe injuries, and occurs in 3\%-30\% of retained intraocular foreign body (IOFB) cases. ${ }^{1,2}$ Gram-negative bacteria are a frequent cause of endophthalmitis in IOFB cases. ${ }^{3}$ Multidrug resistance among endophthalmitis isolates is rare, but more common in Gram-negative organisms. ${ }^{4}$ Ochrobactrum species are aerobic, nonfermenting, Gram-negative rods associated with opportunistic infections. O. intermedium is an emerging human pathogen difficult to identify by conventional methods and associated with multidrug resistance. ${ }^{5}$ In the present case, persistent $O$. intermedium endophthalmitis successfully resolved after the administration of intravitreal moxifloxacin.

\section{Case report}

A healthy 34-year-old emmetropic man presented with a 2-day history of pain and worsening vision due to metallic IOFB of the right eye. The metallic IOFB was part of a mechanical wire brush contaminated with soil. A computed tomography scan confirmed metallic IOFB (Figure 1). Visual acuity (VA) was hand motion in the right eye and 20/20 in the left eye. Intraocular pressures were $24 \mathrm{mmHg}$ in the right eye and $11 \mathrm{mmHg}$ in the left eye. A 3+ relative afferent pupillary defect of the right eye was present. Examination was notable for temporal subconjunctival hemorrhage, $3+$ cell and fibrin of the anterior chamber with $0.5 \mathrm{~mm}$ hypopyon, $3+$ vitreous cell, and poor view posteriorly. Urgent vitrectomy, lensectomy, removal of the IOFB, and intravitreal injection of vancomycin and ceftazidime were performed. Intraoperatively, vitreous cells were heavily concentrated around the foreign body, and retinal whitening and hemorrhages were present in all four quadrants. An inferior retinal tear was treated with endolaser photocoagulation and fluid-gas exchange. Postoperatively, the patient was 


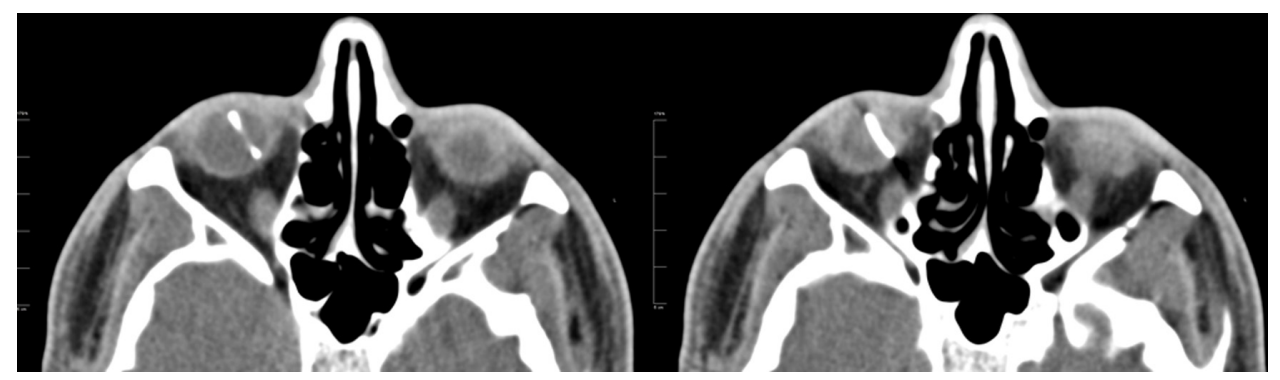

Figure I Axial computed tomography scan of the orbits shows metallic intraocular foreign body of the right eye measuring I4 mm in length.

treated with systemic ciprofloxacin and topical gentamicin, moxifloxacin, prednisolone acetate, and atropine. An initial Gram stain was notable for Gram-negative rods.

Intraocular inflammation worsened over the next 2 days as the hypopyon increased to $2 \mathrm{~mm}$, fibrin reaccumulated in the anterior chamber, and VA remained hand motion. A vitreous tap and injection of vancomycin, ceftazidime, and dexamethasone was performed. Two days later, intraocular inflammation continued to worsen, and the hypopyon increased to $3 \mathrm{~mm}$.

The first vitreous culture showed nonfermenting, Gramnegative rods resistant to amikacin, ampicillin, ampicillin/ sulbactam, ceftazidime, ceftriaxone, gentamicin, piperacillin/ tazobactam, and tobramycin, but sensitive to ciprofloxacin, levofloxacin, and trimethoprim/sulfamethoxazole. The subsequent vitreous culture confirmed persistent endophthalmitis due to a multidrug-resistant Gram-negative rod sensitive to fluoroquinolones. Studies with intravitreal moxifloxacin were reviewed. The benefits, risks, and alternatives, including in vitro safety and potential toxicity of intravitreal moxifloxacin, were discussed thoroughly with the patient. The patient freely consented and received intravitreal moxifloxacin (Vigamox) $0.1 \mathrm{~mL}$ of $500 \mu \mathrm{g} / 0.1 \mathrm{~mL}$.

Over the next week, the hypopyon retracted and the intraocular inflammation resolved. The clear view posteriorly permitted visualization of a macula-involving retinal detachment and choroidal detachment associated with the initial inferior retinal tear. The patient underwent scleral buckle procedure with vitrectomy and silicone oil with repeat injection of intravitreal moxifloxacin $0.1 \mathrm{~mL}$ of $500 \mu \mathrm{g} / 0.1 \mathrm{~mL}$. Culture results obtained at the time of retinal detachment repair were negative, confirming resolution of the endophthalmitis after the administration of intravitreal moxifloxacin. Seven weeks after initial presentation, VA improved to 20/200, and examination showed a quiet anterior chamber with clear view posteriorly (Figure 2). The Mayo Clinic in Rochester identified O. intermedium by performing DNA sequencing of the $16 \mathrm{~S}$ ribosomal DNA (16S rDNA) genes with the first vitreous culture.

\section{Discussion}

Ochrobactrum anthropi has been identified as a rare cause of postoperative endophthalmitis. ${ }^{6,7} \mathrm{O}$. anthropi is the only

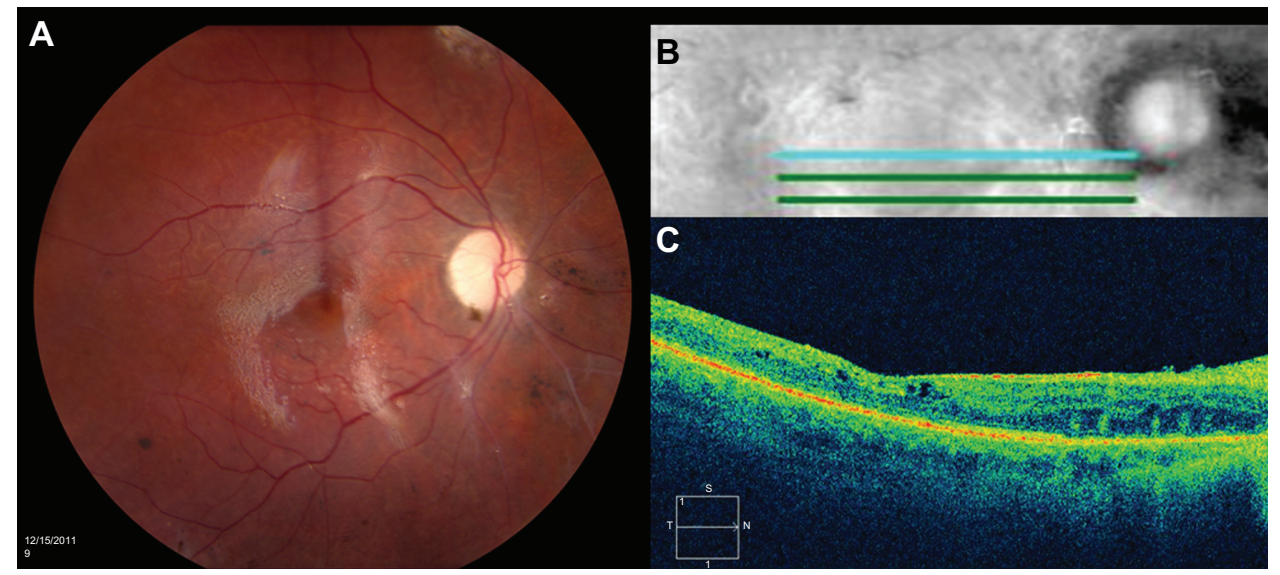

Figure 2 (A) Color fundus photograph of the right eye shows a clear view posteriorly with silicone oil present, sharp disc with I+ pallor, normal vessels, flat macula, and periphery with preserved pigmentation and scattered focal areas of pigment clumping common after retinal detachment. (B) Five-line optical coherence tomography horizontal raster. (C) High-definition optical coherence tomography horizontal image shows preserved foveal contour, intact inner segment-outer segment junction, and trace intraretinal microcysts. 
species of Ochrobactrum in the database of API 20NE, making differentiation of $O$. anthropi and $O$. intermedium difficult. 16S rDNA gene sequencing has been adopted to differentiate $O$. anthropi from $O$. intermedium. ${ }^{8}$ Reported cases of $O$. anthropi endophthalmitis presented 6-9 weeks after cataract extraction, with decreased VA ranging from 20/200 to count fingers, hypopyon, and vitritis. The organisms were resistant to $\beta$-lactams and aminoglycosides. Successful management required vitrectomy in all cases, with some cases also requiring the removal of the intraocular lens and capsule. ${ }^{6,7}$ The present case of Ochrobactrum endophthalmitis differed from previously reported cases, as the presentation occurred 2 days after penetrating injury by contaminated IOFB rather than postcataract extraction. The acute onset of endophthalmitis may be due to the high bacterial load introduced directly into the vitreous at the time of the penetrating injury.

The $O$. intermedium isolate in the present case was multidrug-resistant to both amikacin and ceftazidime, which are commonly used for empiric intravitreal Gram-negative coverage. The $O$. intermedium isolate was sensitive to fluoroquinolones. Moxifloxacin is a fourth-generation fluoroquinolone commonly prescribed topically for endophthalmitis prophylaxis after cataract surgery. ${ }^{9}$

To determine the effective dose of moxifloxacin for intravitreal injection, the half-life and toxicity of moxifloxacin, $90 \%$ minimum inhibitory concentration $\left(\mathrm{MIC}_{90}\right)$ of the causative organism, and vitreous volume of the patient should be considered. Previous studies with moxifloxacin have established $150 \mu \mathrm{g} / \mathrm{mL}$ as a safe concentration for the rabbit eye and human retinal pigment epithelial cells. Intravitreal moxifloxacin caused no electroretinographic or retinal histologic abnormality in rabbit eyes at a concentration of $150 \mu \mathrm{g} / \mathrm{mL}(200 \mu \mathrm{g} / 0.1 \mathrm{~mL}$ injected into a measured vitreous volume of $1.2 \mathrm{~mL}) .{ }^{10}$ In human retinal pigment epithelial cells, there was no evidence of toxicity with a moxifloxacin concentration of $150 \mu \mathrm{g} / \mathrm{mL} .{ }^{11}$ Intravitreal moxifloxacin did demonstrate toxicity in rabbit eyes at a concentration of $213 \mu \mathrm{g} / \mathrm{mL}(320 \mu \mathrm{g} / 0.1 \mathrm{~mL}$ injected into an estimated vitreous volume of $1.5 \mathrm{~mL}){ }^{12}$

The vitreous volume of an adult emmetropic human eye is approximately $4 \mathrm{~mL}$, giving an empiric concentration of $125 \mu \mathrm{g} / \mathrm{mL}$ when $500 \mu \mathrm{g} / 0.1 \mathrm{~mL}$ moxifloxacin is injected intravitreally. Intravitreal moxifloxacin has shown an exponential decay, with a half-life of 1.72 hours. The mean vitreous concentration decreased from $120.5 \mu \mathrm{g} / \mathrm{mL} 1$ hour after injection to $1.1 \mu \mathrm{g} / \mathrm{mL}$ at 12 hours, when $200 \mu \mathrm{g} / 0.1 \mathrm{~mL}$ was administered in rabbit eyes. ${ }^{13}$ The $\mathrm{MIC}_{90}$ in the present case was low, $\leq 1 \mu \mathrm{g} / \mathrm{mL}$ and $\leq 2 \mu \mathrm{g} / \mathrm{mL}$ for ciprofloxacin and levofloxacin, respectively, which may explain the clinical resolution of infection despite the short half-life of intravitreal fluoroquinolones.

Intravitreal moxifloxacin was effective in the management of the present case of bacterial endophthalmitis. In an era of increasing multidrug resistance, intravitreal moxifloxacin may play a role in the management of bacterial endophthalmitis.

\section{Disclosure}

The authors in this paper have no financial or proprietary interests in products, methods, or materials published in this paper.

\section{References}

1. Mieler WF, Ellis MK, Williams DF, Han DP. Retained intraocular foreign bodies and endophthalmitis. Ophthalmology. 1990;97(11): 1532-1538.

2. Parke DW 3rd, Pathengay A, Flynn HW Jr, Albini T, Schwartz SG. Risk factors for endophthalmitis and retinal detachment with retained intraocular foreign bodies. J Ophthalmol. 2012;2012:758526.

3. Yang CS, Lu CK, Lee FL, Hsu WM, Lee YF, Lee SM. Treatment and outcome of traumatic endophthalmitis in open globe injury with retained intraocular foreign body. Ophthalmologica. 2010;224(2):79-85.

4. Pathengay A, Moreker MR, Puthussery R, et al. Clinical and microbiologic review of culture-proven endophthalmitis caused by multidrugresistant bacteria in patients seen at a tertiary eye care center in southern India. Retina. 2011;31(9):1806-1811.

5. Apisarnthanarak A, Kiratisin P, Mundy LM. Evaluation of Ochrobactrum intermedium bacteremia in a patient with bladder cancer. Diagn Microbiol Infect Dis. 2005;53(2):153-155.

6. Song S, Ahn JK, Lee GH, Park YG. An epidemic of chronic pseudophakic endophthalmitis due to Ochrobactrum anthropi: clinical findings and managements of nine consecutive cases. Ocul Immunol Inflamm. 2007;15(6):429-434.

7. Greven CM, Nelson KC. Chronic postoperative endophthalmitis secondary to Ochrobactrum anthropi. Retina. 2001;21(3):279-280.

8. Kämpfer P, Citron DM, Goldstein EJ, Scholz HC. Difficulty in the identification and differentiation of clinically relevant Ochrobactrum species. J Med Microbiol. 2007;56(Pt 11):1571-1573.

9. Jensen MK, Fiscella RG, Moshirfar M, Mooney B. Third- and fourthgeneration fluoroquinolones: retrospective comparison of endophthalmitis after cataract surgery performed over 10 years. J Cataract Refract Surg. 2008;34(9):1460-1467.

10. Gao H, Pennesi ME, Qiao X, et al. Intravitreal moxifloxacin: retinal safety study with electroretinography and histopathology in animal models. Invest Ophthalmol Vis Sci. 2006;47(4):1606-1611.

11. Kernt M, Neubauer AS, Ulbig MW, Kampik A, Welge-Lüssen U. In vitro safety of intravitreal moxifloxacin for endophthalmitis treatment. $J$ Cataract Refract Surg. 2008;34(3):480-488.

12. Aydin E, Kazi AA, Peyman GA, Esfahani MR. Intravitreal toxicity of moxifloxacin. Retina. 2006;26(2):187-190.

13. Iyer MN, He F, Wensel TG, Mieler WF, Benz MS, Holz ER. Clearance of intravitreal moxifloxacin. Invest Ophthalmol Vis Sci. 2006;47(1): 317-319. 


\section{Publish your work in this journal}

Clinical Ophthalmology is an international, peer-reviewed journal covering all subspecialties within ophthalmology. Key topics include: Optometry; Visual science; Pharmacology and drug therapy in eye diseases; Basic Sciences; Primary and Secondary eye care; Patient Safety and Quality of Care Improvements. This journal is indexed on
PubMed Central and CAS, and is the official journal of The Society of Clinical Ophthalmology (SCO). The manuscript management system is completely online and includes a very quick and fair peer-review system, which is all easy to use. Visit http://www.dovepress.com/ testimonials.php to read real quotes from published authors. 